\title{
On Correlating Mixed Forest Fuel Bed Fire Spread Data
}

\author{
Jiann C. Yang
}

This publication is available free of charge from:

https://doi.org/10.6028/NIST.TN.2062

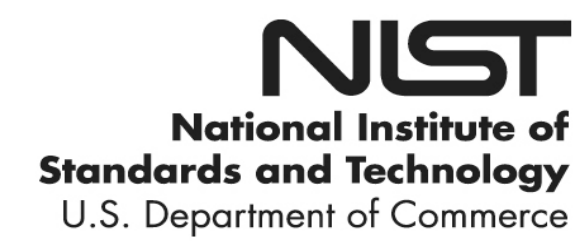




\title{
On Correlating Mixed Forest Fuel Bed Fire Spread Data
}

\author{
Jiann C. Yang \\ Fire Research Division \\ Engineering Laboratory
}

This publication is available free of charge from:

https://doi.org/10.6028/NIST.TN.2062

September 2019

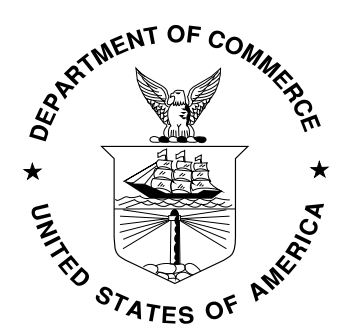

U.S. Department of Commerce Wilbur L. Ross, Jr., Secretary 
Certain commercial entities, equipment, or materials may be identified in this document in order to describe an experimental procedure or concept adequately. Such identification is not intended to imply recommendation or endorsement by the National Institute of Standards and Technology, nor is it intended to imply that the entities, materials, or equipment are necessarily the best available for the purpose.

National Institute of Standards and Technology Technical Note 2062 Natl. Inst. Stand. Technol. Tech. Note 2062, 16 pages (September 2019) CODEN: NTNOEF

This publication is available free of charge from: https://doi.org/10.6028/NIST.TN.2062 


\begin{abstract}
Mixing rules are proposed and used to correlate well-mixed forest fuel bed fire spread data from the literature using the dimensionless correlations previously developed for singlespecies forest fuel bed fire spread with the help of dimensional analysis and the resulting dimensionless groups. The mixing rules provide means to treat well-mixed fuels as pseudo single-species fuels. As a first attempt with very limited experimental data, the dimensionless correlations for single-species fuels may be applicable to mixed-species fuels with proper mixing rules.
\end{abstract}

\title{
Key words
}

Dimensional analysis; fire spread; forest fuels; wildfires. 


\section{Table of Contents}

1. Introduction ......................................................................................................................... 1

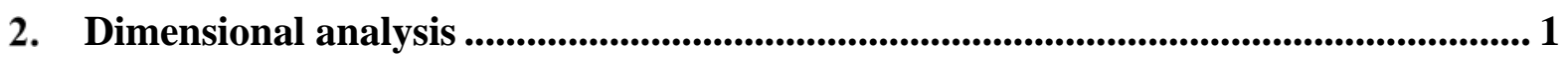

2.1. Single fuel species $i$.................................................................................... 1

2.2. Mixed fuel species.................................................................................. 2

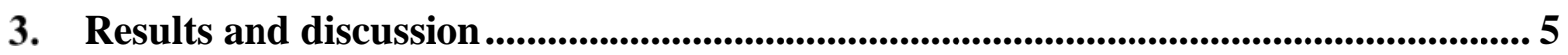

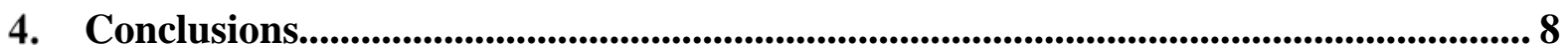

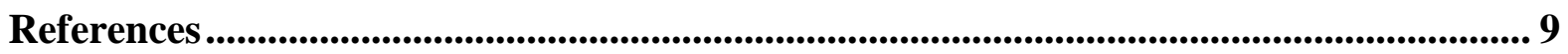

\section{List of Tables}

Table 1. Parameters used to calculate the dimensionless groups for the correlations extracted from Catchpole et al. [15]...................................................................................... 6

\section{List of Figures}

Fig. 1. Illustration of fire spread along a forest fuel bed. ...................................................... 2

Fig. 2. Dimensionless correlation for forest fuel fire spread under wind conditions. ............... 7

Fig. 3. Dimensionless correlation for forest fuel fire spread under no wind conditions. .......... 8 


\section{Glossary}

$\begin{array}{ll}c_{p} & \text { fuel heat capacity }(\mathrm{J} / \mathrm{kg}-\mathrm{K}) \\ k & \text { fuel thermal conductivity }(\mathrm{W} / \mathrm{m}-\mathrm{k}) \\ w & \text { mass fraction (--) } \\ X & \text { volume fraction (--) } \\ A_{b} & \text { exposed fuel surface area (m2) } \\ F_{l d} & \text { fuel loading density (kg/m2) } \\ M & \text { moist fuel mass (kg) } \\ M_{w} & \text { water content of fuel (kg) } \\ M C & \text { wet-basis moisture content of fuel (--) } \\ S_{p} & \text { fire spread rate (m/s) } \\ U & \text { wind speed (m/s) } \\ V & \text { fuel volume (m³) } \\ V_{b} & \left.\text { fuel bed volume (m }{ }^{3}\right)\end{array}$

Greek symbols

$\alpha \quad$ fuel thermal diffusivity $\left(\mathrm{m}^{2} / \mathrm{s}\right)$

$\beta \quad$ fuel volume-to-surface ratio (m)

$\delta_{b} \quad$ fuel bed thickness (m)

$\varepsilon_{b} \quad$ fuel bed void fraction (--)

$\theta \quad$ inclined angle of fuel bed $\left(^{\circ}\right)$

$\rho \quad$ fuel density $\left(\mathrm{kg} / \mathrm{m}^{3}\right)$

$\rho_{b} \quad$ fuel bed bulk density $\left(\mathrm{kg} / \mathrm{m}^{3}\right)$

$\sigma \quad$ fuel surface-to-volume ratio $\left(\mathrm{m}^{-1}\right)$

\section{Subscripts}

$i \quad$ fuel species i in mixed fuel containing $N$ species 


\section{Introduction}

Fire spread along forest fuel beds is an important aspect in the study of wildland fire dynamic behavior. Most, if not all, of the previous experimental studies have been focused on fire spread along a homogeneous fuel bed. The experimental parameters examined mainly included fuel type, fuel bed compactness, applied wind speed, and the orientation of the fuel bed. Refs. [1-14] are representative experimental studies reported in the literature. Very few studies employed well-mixed forest fuel bed. To the best of the author's knowledge, only two experimental studies have been published in the literature. The fire spread experiments conducted by Catchpole et al. [15] were the first to employ mixed forest fuel composed of two species. Viegas et al [16] later extended the mixed fuel components from two species to four species and developed a linear model to correlate fire spread rates for the mixed species fuel beds based on a linear combination of the fire spread rates of individual species weighted by their corresponding mass fractions in the mixed fuel bed. The major assumption used in the model was that the fuel species were heterogeneously distributed (i.e., wellmixed) in the fuel bed. According to Viegas et al. [16], many actual forest fuel beds can be found in configurations that correspond closely to this seemingly idealized fuel bed for mixed species.

Dimensional analysis is a very useful and power tool for correlating experimental data in a meaningful way and reducing experimental efforts. Nelson and Adkins [17] used this technique to correlate the experimental data from their own studies and previous investigators with some success. Pérez et al. [18] used dimensional analysis to develop scaling laws for the effect of wind and slope on the fuel bed fire spread rate. Recently, the author used dimensional analysis to correlate a large amount of experimental data of fire spread along a single-species forest fuel bed from the literature with some success [19]. What is proposed here is to examine if the correlations for single-species fuel could be used for fire spread for mixed forest fuel bed by defining some empirical mixing rules (akin to mixing rules used in thermodynamics for mixtures) to treat well-mixed fuel species as a pseudo single fuel species.

\section{Dimensional analysis}

\subsection{Single fuel species $i$}

In this section, the dimensional analysis for a forest fuel bed of a single fuel species is briefly summarized to provide a preamble to the mixed forest fuel bed analysis. Detailed description of the dimensional analysis can be found in [19] and will not be repeated here. Figure 1 is an illustration of the configuration considered in the analysis. We start by expressing the fire spread rate or rate of spread (ROS) under wind condition as a function of the following controlling variables.

$$
S_{p}=f_{1}\left(A_{b}, \delta_{b}, \alpha, \beta, M, M_{w}, U, \theta\right)
$$

An application of the Buckingham $\pi$-theorem [20] to Eq. (1) by following the systematic calculation procedure described in [21] using matrix operation results in six dimensionless 
groups, which are used to correlate the data from the literature. The following dimensionless correlation is obtained using multiple linear regression analysis [19].

$$
S_{p} \sqrt{A_{b}} / \alpha=1.03 \times 10^{-7}\left(\beta / \sqrt{A_{b}}\right)^{-0.41}\left(M_{w} / M\right)^{-0.82}\left(\delta_{b} / \sqrt{A_{b}}\right)^{-0.29}\left(U \sqrt{A_{b}} / \alpha\right)^{1.32}(\cos \theta)^{-13.98}
$$

Similarly, for no-wind condition, the ROS can be expressed as a function of the following seven independent variables.

$$
S_{p}=f_{2}\left(A_{b}, \delta_{b}, \alpha, \beta, M, M_{w}, \theta\right)
$$

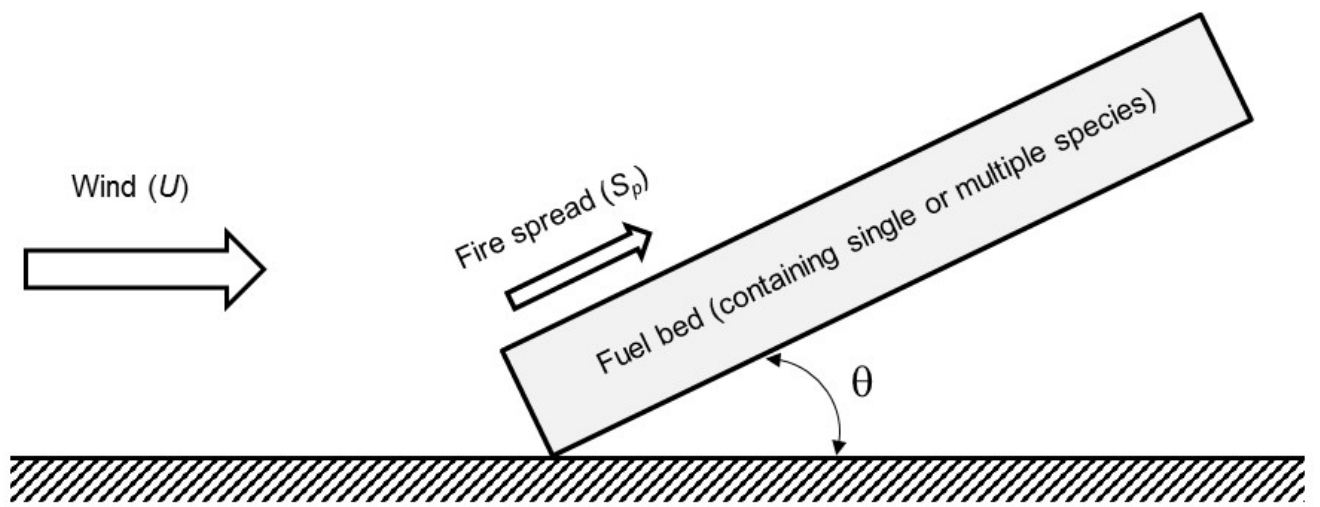

Fig. 1. Illustration of fire spread along a forest fuel bed.

Following the same procedure as that used in the wind condition, the following dimensionless correlation is obtained.

$$
S_{p} \sqrt{A_{b}} / \alpha=0.169\left(\beta / \sqrt{A_{b}}\right)^{-1.27}\left(M_{w} / M\right)^{-0.068}\left(\delta_{b} / \sqrt{A_{b}}\right)^{-0.158}(\cos \theta)^{-6.249}
$$

\subsection{Mixed fuel species}

For a well-mixed forest bed consisted of $N$ fuel species, we have the following relations between mixed fuel properties and individual species properties; some of these relations are definitions, and some can be easily derived.

$$
\begin{gathered}
M=\sum_{i=1}^{N} M_{i} \\
V=\sum_{i=1}^{N} V_{i}
\end{gathered}
$$




$$
\begin{gathered}
w_{i}=M_{i} / \sum_{i=1}^{N} M_{i} \\
x_{i}=V_{i} / \sum_{i=1}^{N} V_{i} \\
\rho_{i}=M_{i} / V_{i} \\
\rho=M / V=\sum_{i=1}^{N} x_{i} \rho_{i} \\
\rho=1 / \sum_{i=1}^{N}\left(w_{i} / \rho_{i}\right) \\
\rho_{b}=\sum_{i=1}^{N} M_{i} / V_{b} \\
F_{l d}=M / A_{b}=\sum_{i=1}^{N} M_{i} / A_{b}=\sum_{i=1}^{N} F_{l d, i} \\
\varepsilon_{b}=\left(V_{b}-V\right) / V_{b}=\left(V_{b}-\sum_{i=1}^{N} V_{i}\right) / V_{b}
\end{gathered}
$$

Note that the void fraction of the fuel bed is related to the packing ratio $\left(\rho / \rho_{b}\right)$ of the fuel bed, a term used frequently in the literature.

$$
\begin{gathered}
\varepsilon_{b}=1-\left(\rho_{b} / \rho\right) \\
\delta_{b}=V_{b} / A_{b}=\left(V_{b} F_{l d}\right) / M
\end{gathered}
$$

or

$$
\begin{gathered}
\delta_{b}=\left(F_{l d} / \rho\right) /\left(1-\varepsilon_{b}\right) \\
\mathrm{MC}=M_{w} / M=\sum_{i=1}^{N} M_{w, i} / \sum_{i=1}^{N} M_{i}=\sum_{i=1}^{N} w_{i} \mathrm{MC}_{i}
\end{gathered}
$$

where the wet-basis moisture content for fuel species $i$ is defined as

$$
\begin{aligned}
\mathrm{MC}_{i} & =M_{w, i} / M_{i} \\
\beta_{i} & =V_{i} / A_{i}
\end{aligned}
$$




$$
\begin{gathered}
\sigma_{i}=1 / \beta_{i}=A_{i} / V_{i} \\
\beta=\sum_{i=1}^{N} V_{i} / \sum_{i=1}^{N} A_{i}=\sum_{i=1}^{N} V_{i} / \sum_{i=1}^{N}\left(V_{i} / \beta_{i}\right)=1 / \sum_{i=1}^{N}\left(x_{i} / \beta_{i}\right) \\
\sigma=1 / \beta=\sum_{i=1}^{N} A_{i} / \sum_{i=1}^{N} V_{i}=\sum_{i=1}^{N} V_{i} \sigma_{i} / \sum_{i=1}^{N} V_{i}=\sum_{i=1}^{N} x_{i} \sigma_{i}
\end{gathered}
$$

Mass fractions are normally given in the literature for mixed fuels, and the mass fraction of species i can be easily converted to volume fraction by

$$
x_{i}=V_{i} / V=\left(M_{i} / \rho_{i}\right) /(M / \rho)=w_{i}\left(\rho / \rho_{i}\right)=w_{i} /\left[\rho_{i} \sum_{i=1}^{N}\left(w_{i} / \rho_{i}\right)\right]
$$

The remaining parameter that needs to be estimated is $\alpha$, which can be considered as an effective thermal diffusivity for the mixed fuel.

$$
\alpha=k /\left(\rho c_{p}\right)
$$

In principle, some form of mixing rules for $k$ and $c_{p}$ could be proposed if $k_{i}$ and $c_{p, i}$ are known. For $c_{p}$, it is reasonable to assume

$$
c_{p}=\sum_{i=1}^{N} w_{i} c_{p, i}
$$

For $k$, two simple empirical mixing rules have been proposed and used in the literature [22], depending on the materials and direction of heat transfer.

$$
\begin{gathered}
k=\sum_{i=1}^{N} x_{i} k_{i} \\
1 / k=\sum_{i=1}^{N}\left(x_{i} / k_{i}\right)
\end{gathered}
$$

Although one could have tried the above mixing rules for $\rho, c_{p}$, $k$ to estimate $\alpha$ and tested their applicability in the correlations, no attempt was made here because the thermal diffusivities for many selected wood species only decrease slightly with density and over a range of moisture contents typically used in experiments reported in the literature. For simplicity and illustrative purpose, a constant thermal diffusivity is assumed. A nominal thermal diffusivity of $1.6 \times 10^{-7} \mathrm{~m}^{2} / \mathrm{s}$ [23] was used for all the fuel species in this work. 


$$
\alpha \approx \alpha_{1} \approx \alpha_{2} \approx \cdots \approx \alpha_{N}
$$

\section{Results and discussion}

The mixed fuel fire spread data from Catchpole et al. [15] were used to illustrate the applicability of the proposed mixing rules for mixed fuels. Unfortunately, the results from Viegas et al. [16], albeit extensive and good quality, could not be used directly here because some of the experimental parameters and conditions needed to calculate the dimensionless groups for the correlations were not fully described or given in their paper. In addition, the paper by Viegas et al. [16] is a culmination of many sets of fire spread experiments conducted by several researchers over many years under many different conditions, making educated guesses on some of the fuel bed parameters very challenging, if not impossible.

In the fire spread experiments conducted by Catchpole et al. [15], the fuel bed width was 1 $\mathrm{m}$, and the bed lengths ranged from $4.7 \mathrm{~m}$ to $7 \mathrm{~m}$. The mixed fuel beds were constructed by uniformly distributing excelsior, cut from Populus tremuloides, throughout an array of equallength vertical pine (Pinus ponderosa) sticks with pre-determined spacing to control packing ratio. The excelsior fuel was packed to a depth equal to the height of the sticks. The fuel bed was oriented horizontally $\left(\theta=0^{\circ}\right)$. Experiments were performed under wind or no-wind conditions. Table 1 summarizes the parameters used to correlate the fire spread data taken from Catchpole et al. [15] or calculated using the mixing rules described above. The parameter estimation process was also facilitated by Viegas et al. [16], who had extracted from Catchpole et al. [15] some of the parameters that could be directly used in this study.

Figures 2 and 3 show the dimensionless correlations based on Eq. (2) and Eq. (4) respectively for the two-species fuel beds used in Catchpole et al. [15]. Single species fuel results summarized by Yang [19] are also plotted in Figs 2 and 3 for reference and comparison. For single species fuels, a total of 334 data points for wind condition (Fig. 2) and 319 data for no-wind conditions (Fig. 3) from various sources [1-14] were used. Note that the best fits in both figures do not include the data from Catchpole et al. [15]. The correlation under wind condition correlate the experimental data slightly better than the nowind condition; this could be due to the fact that less information needed to evaluate the dimensionless groups was given or available in the studies with no-wind, and more nominal values and informed estimates had to be used for some of the parameters in the calculations [19]. In addition, the fire spread rates measured under wind conditions are more pronounced and less ambiguous, thus reducing the measurement uncertainties. 
Table 1. Parameters used to calculate the dimensionless groups for the correlations extracted from Catchpole et al. [15].

\begin{tabular}{lllllllll}
\hline Fuel & $\boldsymbol{w}_{\mathbf{1}}$ & $\boldsymbol{w}_{\mathbf{2}}$ & $\boldsymbol{A}_{\boldsymbol{b}}$ & $\boldsymbol{\delta}_{\boldsymbol{b}}(\mathbf{m})$ & $\boldsymbol{\beta} \mathbf{( m )}$ & $\boldsymbol{M}_{\boldsymbol{w}} / \boldsymbol{M}$ & $\boldsymbol{U}(\mathbf{m} / \mathbf{s})$ & $\boldsymbol{S}_{\boldsymbol{p}}(\mathbf{m} / \mathbf{s})$ \\
\hline excelsior & 1 & 0 & 5.85 & 0.15 & $1.32 \mathrm{E}-04$ & 0.055 & 0.9 & $1.15 \mathrm{E}-01$ \\
sticks & 0 & 1 & 5.85 & 0.15 & $1.59 \mathrm{E}-03$ & 0.070 & 0.9 & $2.28 \mathrm{E}-02$ \\
mixture & 0.469 & 0.531 & 5.85 & 0.15 & $2.45 \mathrm{E}-04$ & 0.063 & 0.9 & $3.20 \mathrm{E}-02$ \\
excelsior & 1 & 0 & 5.85 & 0.15 & $1.32 \mathrm{E}-04$ & 0.055 & 1.8 & $1.33 \mathrm{E}-01$ \\
sticks & 0 & 1 & 5.85 & 0.15 & $1.59 \mathrm{E}-03$ & 0.070 & 1.8 & $3.78 \mathrm{E}-02$ \\
mixture & 0.469 & 0.531 & 5.85 & 0.15 & $2.45 \mathrm{E}-04$ & 0.063 & 1.8 & $6.13 \mathrm{E}-02$ \\
excelsior & 1 & 0 & 5.85 & 0.15 & $1.32 \mathrm{E}-04$ & 0.055 & 2.7 & $2.25 \mathrm{E}-01$ \\
sticks & 0 & 1 & 5.85 & 0.15 & $1.59 \mathrm{E}-03$ & 0.070 & 2.7 & $5.67 \mathrm{E}-02$ \\
mixture & 0.469 & 0.531 & 5.85 & 0.15 & $2.45 \mathrm{E}-04$ & 0.063 & 2.7 & $9.02 \mathrm{E}-02$ \\
mixture & 0.469 & 0.531 & 5.85 & 0.15 & $2.45 \mathrm{E}-04$ & 0.063 & 0.9 & $6.07 \mathrm{E}-02$ \\
mixture & 0.469 & 0.531 & 5.85 & 0.15 & $2.45 \mathrm{E}-04$ & 0.063 & 1.8 & $8.92 \mathrm{E}-02$ \\
mixture & 0.469 & 0.531 & 5.85 & 0.15 & $2.45 \mathrm{E}-04$ & 0.063 & 2.7 & $1.46 \mathrm{E}-01$ \\
excelsior & 1 & 0 & 5.85 & 0.075 & $1.32 \mathrm{E}-04$ & 0.055 & 1.1 & $1.19 \mathrm{E}-01$ \\
sticks & 0 & 1 & 5.85 & 0.075 & $1.59 \mathrm{E}-03$ & 0.070 & 1.1 & $3.78 \mathrm{E}-02$ \\
mixture & 0.469 & 0.531 & 5.85 & 0.075 & $2.45 \mathrm{E}-04$ & 0.063 & 1.1 & $5.22 \mathrm{E}-02$ \\
excelsior & 1 & 0 & 5.85 & 0.15 & $1.32 \mathrm{E}-04$ & 0.055 & 0 & $1.98 \mathrm{E}-02$ \\
mixture & 0.469 & 0.531 & 5.85 & 0.15 & $2.45 \mathrm{E}-04$ & 0.063 & 0 & $1.05 \mathrm{E}-02$ \\
excelsior & 1 & 0 & 5.85 & 0.15 & $1.32 \mathrm{E}-04$ & 0.055 & 0 & $1.98 \mathrm{E}-02$ \\
sticks & 0 & 1 & 5.85 & 0.15 & $1.59 \mathrm{E}-03$ & 0.070 & 0 & $4.83 \mathrm{E}-03$ \\
mixture & 0.469 & 0.531 & 5.85 & 0.15 & $2.45 \mathrm{E}-04$ & 0.063 & 0 & $1.35 \mathrm{E}-02$ \\
excelsior & 1 & 0 & 5.85 & 0.075 & $1.32 \mathrm{E}-04$ & 0.055 & 0 & $1.45 \mathrm{E}-02$ \\
sticks & 0 & 1 & 5.85 & 0.075 & $1.59 \mathrm{E}-03$ & 0.070 & 0 & $2.17 \mathrm{E}-03$ \\
mixture & 0.469 & 0.531 & 5.85 & 0.075 & $2.45 \mathrm{E}-04$ & 0.063 & 0 & $1.17 \mathrm{E}-02$ \\
\hline
\end{tabular}




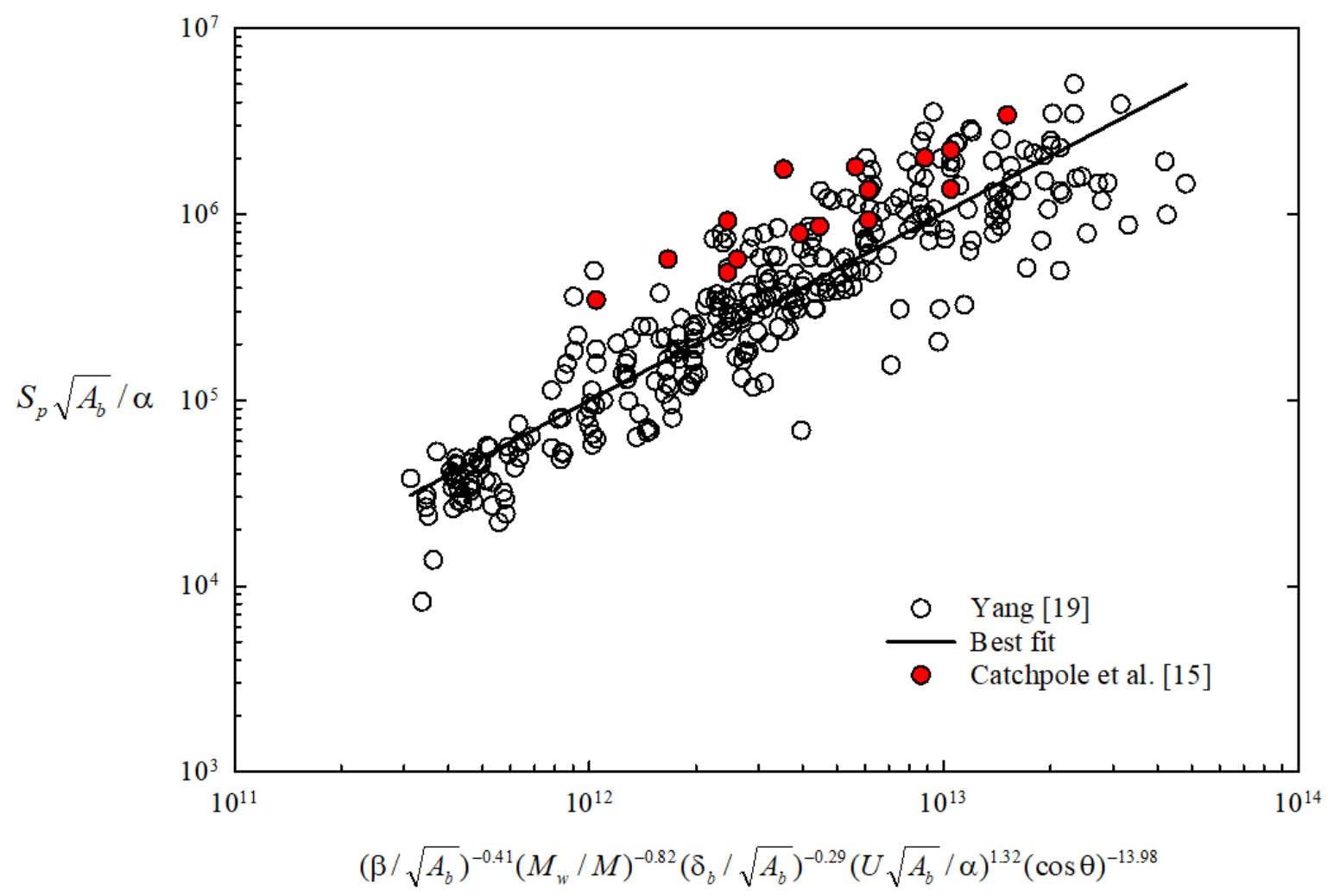

Fig. 2. Dimensionless correlation for forest fuel fire spread under wind conditions. 


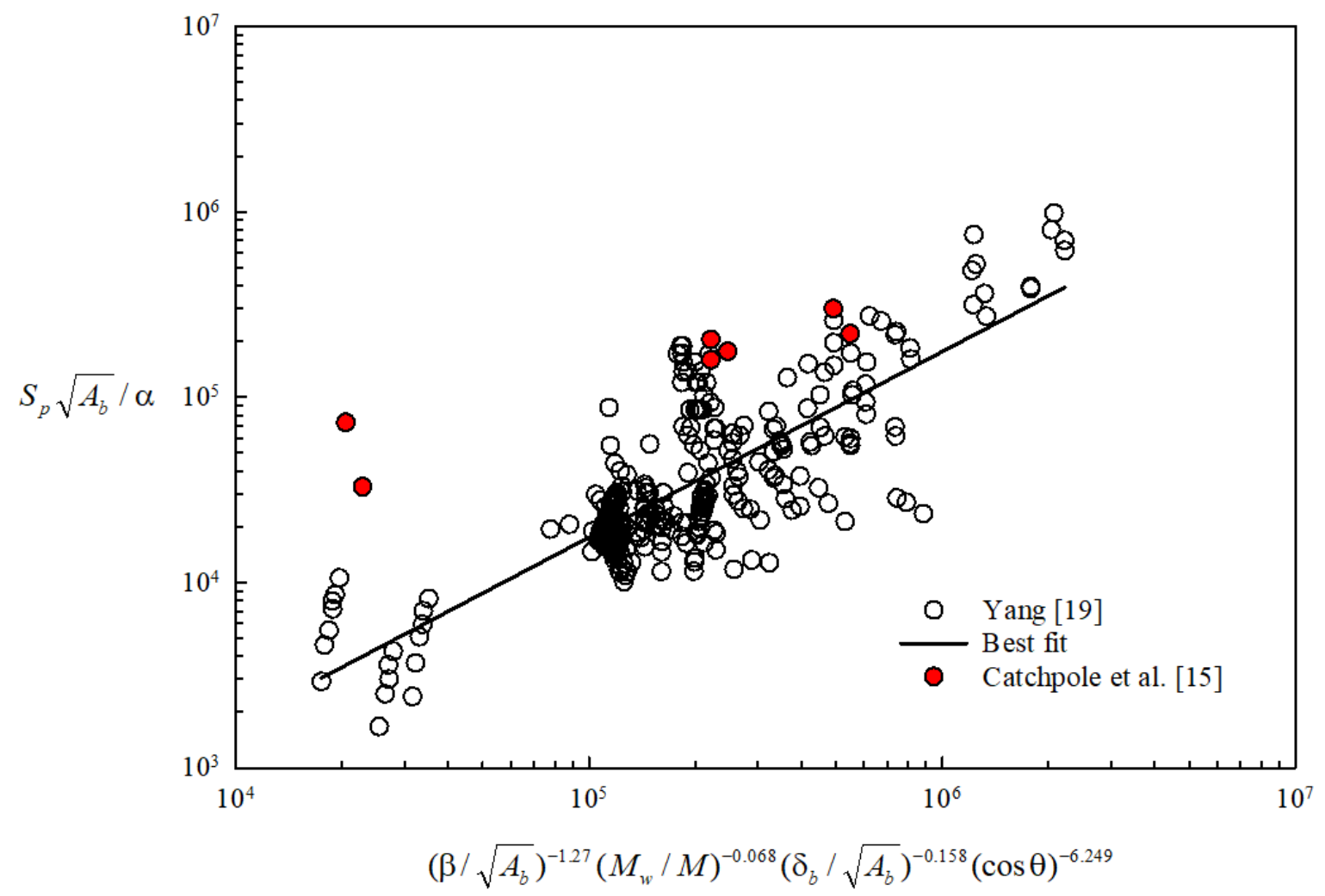

Fig. 3. Dimensionless correlation for forest fuel fire spread under no wind conditions.

\section{Conclusions}

Mixing rules are proposed and used to correlate mixed forest fuel bed fire spread data from the literature using the dimensionless correlations previously developed for single-species forest fuel bed fire spread with the help of dimensional analysis and the resulting dimensionless groups. The mixing rules allow mixed fuels to be treated as pseudo singlespecies fuels. The dimensionless correlations correlate the fire spread rates reasonably well for single-species and multiple-species fuels in the light of the wide range of uncertainties associated with some of the parameters used to obtain the dimensionless groups for the correlations. With proper mixing rules for the fuel bed properties to estimate the dimensionless groups, the correlations for the single-species fuel spreads could be extended and directly applicable to mixed fuel spreads. 


\section{References}

[1] Fons WL (1946) Analysis of fire spread in light forest fuels. Journal of Agricultural Research 72:93.

[2] Beaufait WR (1965) Characteristics of backfires and headfires in a pine needle fuel bed (Intermountain Forest and Range Experiment Station, Forest Service, U.S. Department of Agriculture, Ogden, Utah), U.S. Forest Service Research Note INT39.

[3] Rothermel RC, Anderson HE (1966) Fire spread characteristics determined in the laboratory (Intermountain Forest and Range Experiment Station, Forest Service, U.S. Department of Agriculture, Ogden, Utah), U.S. Forest Service Research Paper INT-30.

[4] Anderson HE, Rothermel RC (1966) Influence of moisture and wind upon the characteristics of free-burning fires. Tenth Symposium (International) on Combustion (The Combustion Institute, Pittsburgh, PA), pp 1009-1019.

[5] Anderson, HE (1969) Heat transfer and fire spread (Intermountain Forest and Range Experiment Station, Forest Service, U.S. Department of Agriculture, Ogden, Utah), U.S. Forest Service Research Paper INT-69.

[6] Fang JB, Steward FR (1969) Flame spread through randomly packed fuel particles. Combustion and Flame 13(4):392-398. https://doi.org/10.1016/00102180(69)90108-4

[7] Nelson RM, Adkins CW (1986) Flame characteristics of wind-driven surface fires. Canadian Journal of Forest Research 16(6):1293-1300. https://doi.org/10.1139/x86-229

[8] Weise DR, Biging GS (1994) Effects of wind velocity and slope on fire behavior. Fire Safety Science 4:1041-1051. http://dx.doi.org/10.3801/IAFSS.FSS.4-1041

[9] Viegas DX (2004) Slope and wind effects on fire propagation. International Journal of Wildland Fire 13(2):143-156. https://dx.doi.org/10.1071/WF03046

[10] Dupuy J-L (1995) Slope and fuel load effects on fire behavior: Laboratory experiments in pine needles fuel beds. International Journal of Wildland Fire 5(3):153-164. https://dx.doi.org/10.1071/WF9950153

[11] Simeoni A, Santoni PA, Larini M, Balbi JH (2001) On the wind advection influence on the fire spread across a fuel bed: Modelling by a semi-physical approach and testing with experiments. Fire Safety Journal 36(5):491-513. https://dx.doi.org/10.1016/S0379-7112(00)00063-1

[12] Anderson WR, Catchpole EA, Butler BW (2010) Convective heat transfer in fire spread through fine fuel beds. International Journal of Wildland Fire 19(3):284298. https://dx.doi.org/10.1071/WF09021

[13] Dupuy J-L, Maréchal J (2011) Slope effect on laboratory fire spread: Contribution of radiation and convection to fuel bed preheating. International Journal of Wildland Fire 20(2):289-307. https://doi.org/10.1071/WF09076

[14] Weise DR, Zhou X, Mahalingam S, Chong J (2015) Marginal fire spread in live fuel beds - horizontal fuels. Fort Collins, CO: Forest Service Research Data Archive. https://doi.org/10.2737/RDS-2015-0007

[15] Catchpole EA, Catchpole WR, Rothermel RC (1993) Fire behavior experiments in mixed fuel complexes. International Journal of Wildland Fire 3(1):45-57. https://doi.org/10.1071/WF9930045 
[16] Viegas DX, Almeida M, Miranda AI, Ribeiro LM (2010) Linear model for spread rate and mass loss rate for mixed-size fuel beds. International Journal of Wildland Fire 19(5):531-540. https://doi.org/10.1071/WF09007

[17] Nelson RM, Adkins CW (1988) A dimensionless correlation for the spread of winddriven fires. Canadian Journal of Forest Research 18(4):391-397. https://doi.org/10.1139/x88-058

[18] Pérez Y, Pastor E, Àgueda A, Planas E (2011) Effect of wind and slope when scaling the forest fires rate of spread of laboratory experiments. Fire Technology 47(2):475-489. https://doi.org/10.1007/s10694-010-0168-7

[19] Yang JC (2018) Dimensional analysis on forest fuel bed fire spread. Canadian Journal of Forest Research 48(1):105-110. https://doi.org/10.1139/cjfr-2017-0049

[20] Buckingham E (1914) On physically similar systems; illustrations of the use of dimensional equations. Physical Review 4(4):345-376. https://doi.org/10.1103/PhysRev.4.345

[21] Langhaar HL (1951) Dimensional Analysis and Theory of Models (John Wiley and Sons).

[22] Kingery WD (1959) Thermal conductivity: xiv, conductivity of multicomponent systems. Journal of the American Ceramic Society 42(12):617-627. https://doi.org/10.1111/j.1151-2916.1959.tb13583.x

[23] Glass SV, Zelinka SL (2010) Moisture relations and physical properties of wood. General Technical Report FPL-GTR-190 Wood handbook: wood as an engineering material, ed Ross RJ (Forest Products Laboratory, Forest Service, U.S. Department of Agriculture, Madison, WI 53726). 